\title{
Tactical Procurement Planning under Uncertainty in Aromatic Coconut Manufacturing
}

\author{
Siraprapha Deepradit ${ }^{1}$, Pornthipa Ongkunaruk ${ }^{2 *}$, Roongrat Pisuchpen ${ }^{1}$ \\ ${ }^{1}$ Department of Industrial Engineering, Faculty of Engineering, Kasetsart University, 50 Ngam Wong Wan \\ Rd, Lat Yao, Chatuchak, Bangkok 10900, Thailand \\ ${ }^{2}$ Department of Agro-Industrial Technology, Faculty of Agro-Industry, Kasetsart University, 50 Ngam Wong \\ Wan Rd, Lat Yao, Chatuchak, Bangkok 10900, Thailand
}

\begin{abstract}
This article presents a tactical procurement plan for an aromatic coconut manufacturer located in Thailand using a mathematical model. Procurement planning is complex because many uncertainty factors are dependent upon the delivery schedule and season, which affect the price of the coconut and the quantity of the order. There were two alternatives for procurement: farmers and coconut collectors. The model used in this research study compared four scenarios: three deterministic models in which every parameter is constant under the worst-case, best-case, and average-case scenarios and a stochastic model simulation. For the deterministic models, the mixedinteger linear programming (MILP) was formulated in a spreadsheet and solved using the Frontline Premium Solver in Excel. In the second model, a Monte Carlo simulation-based MILP with three random variables-demand, price, and the number of coconuts-was solved optimally. The solution indicates how many coconuts will be purchased from farmers and collectors and which truck will be used to deliver the order to maximize total annual profit. The results were compared among four scenarios that could help decision-makers consider the range of profit. The results showed that the stochastic model resulted in less profits than the deterministic model. In the worstcase scenario, profit was lost; in the best-case scenario, profit was gained. In the stochastic model, profits were increasing, except in July. In summary, procurement planning helps factories and farmers realize the price, supply quantity, and demand uncertainties and organize to respond optimally. Proper farm management could increase the productivity of the farm and lessen the supply shortage, resulting in a higher profit. The findings of this research could be applied to assist coconut processors' supply planning efforts; moreover, proper farm management could increase the farm's productivity and lessen the supply shortage.
\end{abstract}

Keywords: Agriculture; Aromatic coconut; Mixed integer linear programming; Monte Carlo simulation; Procurement

\section{Introduction}

Aromatic coconut is a popular Thai export crop in the world market because its smell and taste are unique. The number of consumers of aromatic coconut is increasing rapidly due to its health benefits. Although the aromatic coconuts are ranked ninth in exports worldwide (Pipatkanaporn, 2016), and there is an increasing trend, supply still cannot satisfy the demand. The supply chain planning for agricultural products is complex due to 
several uncertainty factors, such as the quantity of the supply, the demand, and purchase prices. Most of these factors depend on seasonality. Moreover, there is a lack of production planning and marketing data in the aromatic coconut supply chain (Gajasuta et al., 2017). Procurement is one of the primary functions of planning, and it is related to purchasing decisions, such as when to procure the product, how many items to order, and from what sources (Bahinipati, 2014; Ogwang and Waweru, 2017). One of the procurement decisions is the make-or-buy decision. This decision helps reduce costs and improve return on assets when combined with heated competition from third-party suppliers. Onyango (2012) examined the effects of procurement planning, Miriti (2018) proposed the effect of procurement planning on supply chain performance in the Kenyan healthcare system, and Chepkesis et al. (2018) indicated the effects of procurement planning on suppliers' performance in public institutions. Willy and Njeru (2014) investigated the effects of agricultural procurement planning in the agricultural supply chain.

Many researchers have improved agri-food supply chain management using several tools, of which mixed-integer linear programming (MILP) is the most popular. For example, Chueprasert et al. (2016) identified and resolved the optimal raw milk blending problem for a milk collecting center in Thailand. Ongkunaruk and Ongcunaruk (2015) proposed using MILP to address the coconut sap pickup problem with time windows for a coconut sap juice manufacturer. Dems et al. (2016) studied a wood procurement planning problem in Eastern Canada using MILP. Limpianchob (2017) integrated the harvesting and production plan of aromatic coconut using MILP. Kostin et al. (2018) studied how to use MILP to plan the Brazilian bioethanol supply chains and optimize the net present value of the entire supply chains for the sugar and bioethanol sectors in Brazil. Vanzetti et al. (2019) used MILP to develop an integrated approach for bucking planning, such as the number of stems to be harvested and sawmill production planning, i.e. the used cutting patterns in the forest industry. In real-world situations, stochastic planning is more appropriate than deterministic planning because many factors are uncertain. Govindan and Cheng (2018) studied the advances in stochastic programming and robust optimization for supply chain planning, and Jareonkitpoolpol et al. (2018) determined the optimal blending problem of organic-chemical fertilizer using Monte Carlo simulation. Aziz et al. (2018) used Monte Carlo simulation to improve concrete composites for enhanced X-ray/gamma-ray radiation shielding. Wicaksono et al. (2019) presented the Monte Carlo simulation of net present value based on natural gas price uncertainty and production reservoir capacity. Yatmo et al. (2018) analyzed the occurrence of airborne transmission in healthcare waiting areas. Simulation is also a useful process improvement tool in agro-industry; for example, Pisuchpen and Ongkunaruk (2016) simulated the production of a large-sized frozen chicken manufacturer and proposed a new process for line balancing. Doungpattra et al. (2012) reduced the cost of pallet transport for a pet food manufacturer by simulation the process.

The aromatic coconut supply chain of a factory consists of farmers, harvesters, collectors, manufacturers, retailers, wholesalers, and domestic consumers and importers for international trade, as shown in Figure 1. Supply chain management includes supply chain planning, procurement, transportation management from harvesting areas to the factory, production, and transportation for the product, distribution, and customer management.

Procurement planning is an important activity because it addresses the operation costs and helps a factory reduce costs. For aromatic coconut supply chains, procurement sources include harvesting at contracted farms and purchasing from local collectors. Each source has different advantages and disadvantages. 


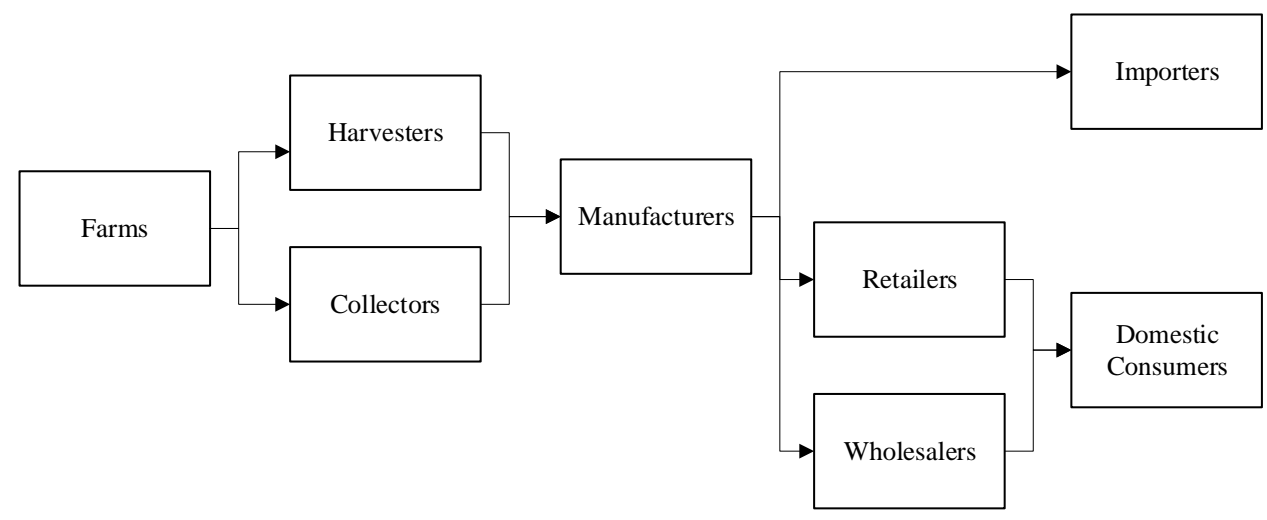

Figure 1 An aromatic coconut supply chain in Thailand

Purchasing costs are lower when coconuts are procured from contracted farms instead of collectors, but this also entails transportation and harvesting costs. Although purchasing from collectors results in the highest purchasing prices, it is essential to do so when there is high demand and the supply from contract farms is insufficient. Four-wheel trucks and six-wheel trucks are used to transport coconuts from contracted farms. A factory must plan when and how many coconuts to harvest from contracted farms located near its facility. Moreover, the factory needs to decide whether to purchase coconuts from collectors during the peak season. The challenge is that the number of available coconuts from contracted farms and collectors and the purchasing prices fluctuate. At present, the harvest plan is made based on experience, and it is impacted by unbalanced supply and demand. Thus, our objective is to solve the make-or-buy decision with the truck allocation problem to maximize profit under conditions of uncertainty.

This paper extends the existing results from the deterministic model of Kanjanarat and Ongkunaruk (2014) by using the MILP and the simulation model planning of Deepradit et al. $(2017,2018)$ who studied the harvest plans for aromatic coconut manufacturing. In our study, we used the Monte Carlo simulation to determine the appropriate harvest age. The model sought the maximum annual profit for fixed period and varied period constraints. The objective was to improve the procurement planning methods under uncertainty factors for aromatic coconut manufacturing in the Ratchaburi Province of Thailand. The solution maximized the total profit. A deterministic model using the Frontline Premium Solver and the stochastic model using Oracle Crystal Ball were presented and compared.

\section{Methodology}

First, we collected data, such as the fluctuated supply quantity and seasonality of the aromatic coconut, the current supply chain, the coconut price from procurement sources, and the market prices, by interviewing agricultural extensionists and agricultural officers of the Ratchaburi Provincial Agricultural Extension Office of the Ministry of Agriculture and Cooperatives, factory managers, and farmers; we also accessed data from http://www.ratchaburi.doae.go.th and http://www.taladsimummuang.com, conducted a literature review, and assessed the findings reported in academic papers. Second, we separated the data into two groups: constant data and uncertainty data. The uncertainty data fluctuated, such as demand or customers' order quantity, supply quantity, aromatic coconut purchasing price from collectors, and the selling price. Third, we chose appropriate methods to analyze the data. We analyzed their patterns using Input Analyzer. The most appropriate distribution was chosen using the $\mathrm{p}$-value that was greater than or equal to the 0.05 significance level. Then, we chose the techniques for accurate forecasting (Pradita et 
al., 2020). The Holt-Winters' method was used for forecasting the purchasing prices at contracted farms in the next year, and the method was chosen that had the least mean absolute square error (Richard and Koehler, 2005). Next, the MILP was created in an Excel spreadsheet based on assumptions about the real-world situation. The Frontline Premium Solver was used for the deterministic model and Oracle Crystal Ball was used for the stochastic simulation model. To ensure that the model result is correct, we verified and validated the model by testing a small version of the current problem. Finally, we analyzed the worst-case scenarios and the best-case scenarios that assigned uncertainty parameters, as seen in Table 1, and we assumed that the prices in the same month were constant. In the worst-case scenario, the demand was at its maximum level, the coconut price was the highest, and the selling price was the lowest, but the supply was at a minimum level, which means the supply was insufficient. In the best-case scenario, the demand and supply quantities were at a maximum, the selling price was the highest, and the coconut price was the lowest; thus, the best possible total profit occurred.

Table 1 The different cases of uncertainty parameters in the deterministic model

\begin{tabular}{lccc}
\hline \multicolumn{1}{c}{ Parameters } & Worst-case & Average-case & Best-case \\
\hline $\begin{array}{l}\text { demand for factory } \\
\text { the number of supply coconuts }\end{array}$ & $\begin{array}{l}\text { aMax } \\
\text { from contracted farms }\end{array}$ & cAvg & Max \\
$\begin{array}{l}\text { the number of supply coconuts } \\
\begin{array}{l}\text { from collectors } \\
\text { the coconut price bought from }\end{array}\end{array}$ & Min & Avg & Max \\
$\begin{array}{l}\text { collectors } \\
\text { the selling price }\end{array}$ & Max & Avg & Max \\
\hline
\end{tabular}

amaximum value, ${ }^{b}$ minimum value and caverage value of the distribution

It is necessary to consider the purchase prices in aromatic coconut harvest planning since the prices fluctuate based on season and demand. The purchase prices at contracted farms were forecasted by collecting historical prices at the factory. The factory only provided data from 2016. Thus, we collected the market prices for aromatic coconuts from http://www.taladsimummuang.com, which provided data from 2013 to 2018. The data showed that the prices vary month-to-month, but the patterns are the same for every year. The objective function included the total purchasing cost to analyze how purchasing price affects the total cost. From May to July, the supply level of aromatic coconuts is low and the price is high. However, from August to October, the supply level of aromatic coconuts is high, which results in a low price. This corresponds to the supply and demand mechanism. Hence, seasonality is an important factor for procurement planning. Then, time series techniques were considered. Although the prices at contracted farms fluctuated, the prices were constant in the same month for both models.

The harvest plan considered the demand, vehicle, and allocation constraints, which were formulated as the MILP. The objective function was to maximize the total profit to satisfy the related constraints under the model assumption as follows. The procurement sources were harvesting at contracted farms and purchasing from collectors. For harvesting at contracted farms, the factory had to allocate vehicles and labor but the purchasing prices are lower than when buying from collectors. In contrast, when purchasing from collectors, the factory will determine how much to buy and the collectors are responsible for the delivery; hence, the purchasing price is higher than when buying from farmers. In this research study, we considered when and how much to buy from the 
two sources because the supply and demand for coconuts fluctuates. The deterministic and stochastic models are described below.

\subsection{Deterministic Model}

All the parameters were constant using the mean of the historical data based on the mathematical model. The Frontline Premium Solver was used to find the solution under three scenarios, as shown in Table 1. The model is a non-smooth optimization problem. An evolutionary algorithm was chosen to find the solutions. Because the uncertainty parameters conformed to their distribution, they were assumed to be constant, as shown in the average case in Table 1 . The uncertainty parameters used the average value of their distributions.

\subsection{Stochastic Simulation Model}

Based on the mathematical model, some uncertainty parameters were generated based on their actual distribution. Then, Oracle Crystal Ball was run for 500 replications and 500 trials with a 95\% confidence interval. OptQuest in Crystal ball was used to create the possible outputs and find the optimum result under uncertainty (Andersen and Brandstrup, 2008). The details are presented below.

\subsubsection{Input analysis}

The uncertainty and forecasted parameters were identified and analyzed. First, data on the number of aromatic coconuts from the contracted farms were collected for 2016 and information about the demand for aromatic coconuts was collected by interviewing the factory managers. The supply and demand for aromatic coconuts fluctuates depending on the season. Analysis of the random variables was important because it affects the simulation results (Banks et al., 2005). Input Analyzer, the standard tool of ARENA, was used to find the most appropriate distribution for the random variables. Input Analyzer selected the distribution type from the histogram and the probability density function of the parameters, and it summarized distributions for which the p-value was greater than the significance level. The distributions of demand $\left(D_{t}\right)$ and the selling price in each season were generated.

\subsubsection{Simulation model}

A Monte Carlo simulation was used to generate the distributions of the uncertainty parameters and optimize the decision variables to maximize the objective function. The stochastic simulations were the average scenarios of the possible total profits. The price of the coconuts purchased from collectors and the selling price were defined from the known distributions. Daily prices were constant in the same month, but the purchasing and selling prices were different in other months.

\subsection{Comparison of the Model Solutions}

The results from the deterministic and the stochastic simulation models were compared. The uncertainty factors or random variables in the deterministic model were replaced with the assigned values presented in Table 1, while the stochastic model simulated the random variables based on their distributions. Four scenarios-the worst, best, average, and simulation cases-were compared to show a wide range of total factory profit under different scenarios.

\section{A Mathematical Model}

The MILP was proposed based on assumptions of the actual situation of an aromatic coconut factory located in Ratchaburi Province, Thailand. The indices and sets, parameters, decision variables, objective function, and constraints are discussed below. 


\subsection{Assumptions}

There were two procurement sources: contracted farms and collectors. The following assumptions were made. First, the harvest areas are independent, and all the coconuts are of good quality. Second, all the vehicles are available throughout the planning horizon. Third, the purchasing prices from the contracted farms and the collectors are constant in the same month, the supply of coconuts from contracted farms, the supply of coconuts from collectors, and the demand have specific distribution parameters in each season. Each model was a monthly planning horizon. These parameters were defined as daily random variables.

\subsection{Indices and Sets}

$k$ is the vehicle index, $t$ is the time index (days), $K$ is a set of vehicles $=\{1, \ldots, N\}$, and $H$ is a set of time horizon $=\{1, \ldots, T\}$.

\subsection{Constant Parameters}

$N$ is the number of vehicles, $T$ is the number of planning horizon (days), $C_{k}$ is the capacity of vehicle $k$ (coconuts per vehicle), $W$ is the number of the coconuts that can be stored per day, $G$ is the maximum number of shipments per day, $F_{k}$ is the fixed cost of vehicle $k$ (USD per round), $A_{k t}$ is the labor cost of vehicle $\mathrm{k}$ at time $t$ (USD per round), $P_{t}$ is the contracted farm's coconut price at time $t$ (USD per coconut), $C_{t}$ is the shortage cost at time $t$ (USD per coconut), $R_{t}$ is the holding cost at time $t$ (USD per coconut), $I_{t}$ is the inventory of coconuts at the end of time $t$ (if the coconut supply is more than the demand), $L_{t}$ is the number of coconuts in shortage at time $t$ (if the coconut supply is less than the demand), $J_{t}$ is the number of coconuts salvaged at time $t$ (if the number of leftover coconuts is more than the maximum warehouse capacity), and $O_{t}$ is the salvage value of coconuts at time $t$ (USD per coconut).

\subsection{Random Variables}

$D_{t}$ is the factory demand at time $t$ (coconuts per day), $S_{t}$ is the number of supply coconuts purchased from contracted farms at time $t, M_{t}$ is the number of supply coconuts purchased from collectors at time $t, Q_{t}$ is the coconut price purchased from collectors at time $t$ (USD per coconut), and $B_{t}$ is the selling price at time $t$ (USD per coconut).

\subsection{Decision Variables}

$X_{t}$ is the number of coconuts harvested from contracted farms at time $t, W_{t}$ is the number of coconuts purchased from collectors at time $t, Z_{k t}$ is the number of shipments at time $t$ for vehicle $k$, and

$$
Y_{k t}=\left\{\begin{array}{l}
1, \text { if vehicle } k \text { is used at time } t \\
0, \text { otherwise }
\end{array}\right.
$$

\subsection{Objective Function and Constraints}

The objective was to maximize the total profit, which was the revenues minus the total costs, as shown in Equation 1. The revenues were the total selling prices multiplied by the number of delivered coconuts. It is the minimum value between the demand plus the number of coconuts in shortage from the previous period and the availability of coconuts. The total costs consisted of the purchasing costs from contracted farm and collectors, the fixed cost for vehicles used, the harvesting labor cost, the shortage cost, and the holding cost.

$$
\begin{aligned}
& \text { Maximize } \sum_{t} B_{t} \times \operatorname{Min}\left(D_{t}+L_{t-1}, X_{t}+W_{t}+I_{t-1}\right)+\sum_{t} O_{t} J_{t}- \\
& \left(\sum_{t} P_{t} X_{t}+\sum_{t} Q_{t} W_{t}+\sum_{k} \sum_{t} F_{k} Z_{k t}+\sum_{k} \sum_{t} A_{k} Y_{k t}+\sum_{t} C_{t} L_{t}+\sum_{t} R_{t} I_{t}\right)
\end{aligned}
$$


Subject to

(6)

$$
\begin{gathered}
X_{t} \leq S_{t}, \forall t \in H \\
W_{t} \leq M_{t}, \forall t \in H \\
X_{t}+W_{t}-I_{t-1}+L_{t} \geq D_{t}+L_{t-1}+I_{t}+J_{t}, \forall t \in H \\
Z_{k t} \leq G Y_{k t}, \forall t \in H, \forall k \in K \\
X_{t} \leq \sum_{k} Z_{k t} C_{k}, \forall t \in H
\end{gathered}
$$

(8)

(10)

$$
\begin{gathered}
I_{t} \leq W, \forall t \in H \\
I_{t}=\left(X_{t}+W_{t}+I_{t-1}\right)-\left(D_{t}+L_{t-1}\right), \text { if } X_{t}+W_{t}+I_{t-1} \geq D_{t}+L_{t-1}, \forall t \in H
\end{gathered}
$$

$$
\begin{gathered}
L_{t}=\left(D_{t}+L_{t-1}\right)-\left(X_{t}+W_{t}+I_{t-1}\right), \text { if } D_{t}+L_{t-1} \geq X_{t}+W_{t}+I_{t-1}, \forall t \in H \\
J_{t}=W-I_{t}, \text { if } W \geq I_{t}, \forall t \in H
\end{gathered}
$$

$$
\begin{gathered}
X_{t}, W_{t} \geq 0, \text { integer }, \forall t \in H \\
Y_{k t}=\text { binary }, \forall k \in K, \forall t \in H \\
Z_{k t}=\text { integer, } \forall k \in K, \forall t \in H, Z_{k t} \in\{0 \ldots G\}
\end{gathered}
$$

Using Equation 2 and Equation 3, the number of coconuts purchased from the contracted farms and collectors are less than the supply quantities. Equation 4 calculates the balanced constraint between the available number of coconuts and the demand. Equation 5 represents the If-then constraint to ensure that the shipment will occur when that vehicle was used. Based on Equation 6, the quantity of harvested coconuts does not exceed the capacity of the vehicles. Equation 7 implies that the inventories did not exceed the maximum warehouse capacity. Then, Equation 8, Equation 9, and Equation 10 are inventory, shortage, and salvage balance equations. If the demand was less than the available coconuts, then inventory occurred. Otherwise, a shortage occurred. Moreover, if the excess inventory was greater than the warehouse capacity, salvage occurred, where the factory will sell coconuts at a lower price. Finally, Equation 11, Equation 12, and Equation 13 are bounds for the decision variables. The MILP was created in Excel and based on assumptions about the real-world situation.

\section{Results and Discussion}

A comparison of the differences in procurement planning using the deterministic and stochastic models is illustrated in Table 2. The total costs consist of the purchasing costs from the contracted farm and collectors, the fixed cost of the vehicles used, the harvesting labor cost, the shortage cost, and the holding cost. Unbalanced supply and demand resulted in inventory or shortage. The model was solved by choosing the procurement sources that led to the lowest costs. The factory has two purchasing options: contracted farms or collectors.

From May to July, the supply of coconuts was lower than the demand; hence, the price was higher than in other seasons (Deepradit et al., 2020). A factory with effective procurement management will earn greater profits. From August to October, the coconut supply increased, so the price was lower. Thus, the factory has to keep the excess supply of 
coconuts as inventory in cold storage, which results in high inventory costs. Furthermore, if the excess supply of coconuts is more than the warehouse capacity, the selling price of the coconuts will be less than the purchasing price (salvage value). This results in lower profits. However, from November to January, the coconut supply usually increases and the price is reduced.

Table 2 The possible total profits $\left(10^{3} \mathrm{USD}^{\mathrm{a}}\right)$ with the deterministic and stochastic models

\begin{tabular}{lrrrr}
\hline Month & Worst-case & Best-case & Deterministic model & Stochastic model \\
\hline Jan. & -595.59 & 334.88 & 217.24 & 180.56 \\
Feb. & -482.65 & 305.48 & 208.17 & 174.80 \\
Mar. & -609.81 & 325.72 & 216.70 & 182.99 \\
Apr. & -568.03 & 318.45 & 203.99 & 191.16 \\
May & -885.70 & 422.74 & 219.87 & 216.78 \\
June & -827.04 & 406.12 & 173.70 & 132.46 \\
July & -885.32 & 423.37 & 42.66 & -37.27 \\
Aug. & -885.58 & 427.76 & 123.92 & 60.17 \\
Sept. & $-1,326.38$ & 325.17 & 209.67 & 196.81 \\
Oct. & $-1,415.68$ & 334.86 & 210.86 & 198.12 \\
Nov. & $-1,326.38$ & 325.87 & 200.38 & 193.26 \\
Dec. & $-1,415.68$ & 338.09 & 226.41 & 198.74 \\
\hline \multicolumn{1}{c}{ Sum } & $-11,223.83$ & $4,288.52$ & $2,250.47$ & $1,991.68$ \\
\hline
\end{tabular}

aCalculated at 30.18 THB per 1 USD

To perform procurement planning for the coconut manufacturer, four scenarios were considered so that the decision-makers will know the range of the output of the possible scenarios. The worst-case scenario occurs under very high demand, but the coconut quantity and the total profit are both low. The best-case scenario occurs under high supply, demand, and the total profit. The profit from the other two scenarios (average-case scenario and simulation-case scenario) ranged between that of the worst-case and best-case scenarios. This information will help decision-makers consider whether they can accept the worst-case results and determine if the best-case results are sufficient. In the worst-case scenario, all the models lose because this case was the worst possible outcome that could occur. The loss was caused by the accumulated backorder cost. This shows that there was a high risk for procurement under uncertainty for the manufacturer under poor procurement management. The deterministic model resulted in a more profitable outcome than the stochastic model because the optimization under constant parameters was more accurate (Limpianchob, 2017). The stochastic model simulated the parameters randomly (Jonkman et al., 2019). Hence, the total profit of the average case was greater in the deterministic model than the stochastic model, as shown in Figure 2.

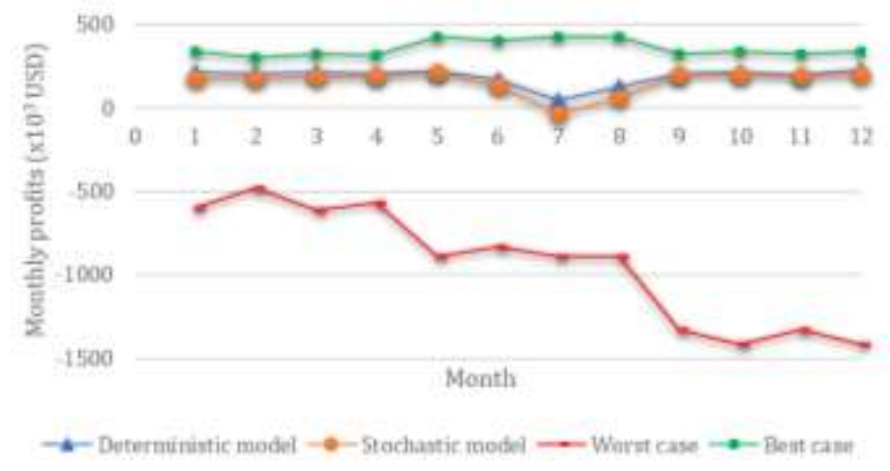

Figure 2 The possible monthly total profit 
Although the stochastic simulation model had less profit than the deterministic model, it showed the likelihood of gaining a positive benefit from 500 trials. Moreover, in the deterministic and stochastic scenarios, the profits started decreasing from June to August because the coconut supply was lower than the demand from May to July. Especially, for the stochastic scenario, in July, the profit was negative, due to the shortage cost. This implies that the factory should handle its supply shortage to prevent loss and balance the demand with the supply. The supply shortage will be critical from May to July; hence, the decisionmakers could adjust their harvesting and procurement plans beforehand. Consequently, proper farm management could increase the farm's productivity and lessen the supply shortage.

We compared the results from the deterministic model of Kanjanarat and Ongkunaruk (2014) and the simulation model of Deepradit et al. (2017), who used the Monte Carlo simulation to seek the maximum annual profit of the aromatic coconut supply chain with two procurement sources: contracted farms and collectors. For the deterministic model, we considered additional parameters, such as holding cost, shortage cost, price, and inventory. Moreover, there were additional constraints on inventory, shortage, and salvage balances. Kanjanarat and Ongkunaruk (2014) used all constant parameters and considered the average-case scenario. For the simulation model, we extended the model of Deepradit et al. (2017) that considered how to harvest a factory farm based on the market price. Furthermore, the objective function was to maximize total revenue from selling at the farm whereas the harvest planning time was quarterly based.

In summary, the factory should purchase from contracted farms when the coconut supply is greater than the customer demand. However, when the supply of coconuts from contracted farms is less than customer demand, factories should procure from collectors to prevent a shortage.

\section{Conclusions}

At present, factories lack stochastic environment planning, which does not conform to real-world situations. In this research study, we proposed an optimal tactical procurement plan for aromatic coconut manufacturing using the MILP under the uncertainty simulation model. Aromatic coconut manufacturing faces planning problems due to supply shortages and unbalanced supply and demand. The procurement plan for aromatic coconuts is complex because it had some uncertainty factors, such as price, demand, and supply quantity. This study's findings impact factory decision-makers and helps then manage uncertainty factors. These factors also significantly impact farm production planning. From May to July, factories face coconut shortage because the supply is insufficient. A factory needs to procure from both contracted farms and collectors. It should also extend the contracted areas to satisfy demand and reduce the risk of shortage, which results in a higher cost. In the future, the stochastic model will use an extended time horizon to plan procurement. The increasing time horizon will increase the variables, scenarios, and processing time. Therefore, future research will attempt to improve stochastic programming by separating it into two-stages or multiple stages (Sawik, 2017; Dillon et al., 2017; Ioannou et al., 2019) to solve larger problems and address more complex systems.

\section{Acknowledgements}

The authors would like to thank the case study company representatives who generously provided us with details about the farmers' processes and input data. 


\section{References}

Andersen, N.J.H., Brandstrup, J., 2008. Monte Carlo Simulation in Crystal Ball 7.3. AARHUS University, Denmark: Analytic Group

Aromatic Coconut Price. Available Online at http://www.taladsimummuang.com, Accessed on December 31, 2019

Aziz, F., Panitra, M., Rivai, A.K., 2018. Synthesis and Monte Carlo Simulation of Improved Concrete Composites for Enhanced X-Ray/Gamma Ray Radiation Shielding. International Journal of Technology, Volume 9(4), pp. 695-706

Bahinipati, B.K., 2014. The Procurement Perspectives of Fruits and Vegetables Supply Chain Planning. International Journal Supply Chain Management, Volume 3(2), pp. 111131

Banks, J., Carson, J.S., Nelson, B.C., Nicol, D.M., 2005. Discrete-Event System Simulation. $4^{\text {th }}$ Edition. London: Pearson Education

Chepkesis, K., Keitany, P., Kiplel, M., 2018. Effect of Procurement Planning on Suppliers Performance in Public Institutions: A Case of Moi University. European Journal of Logistics, Purchasing and Supply Chain Management, Volume 6(2), pp. 1-9

Chueprasert, M., Ongkunaruk, P., Ongcunaruk, W., 2016. The Study of Business Process and Decision Support of Raw Milk Blending for a Collecting Centre in Thailand. International Food Research Journal, Volume 23(3), pp. 1233-1238

Deepradit, S., Ongkunaruk, P., Pisuchpen, R., 2020. The Study of Forecasting Techniques for Aromatic Coconut Monthly Prices using Individual and Hierarchical Forecasting. Thai Journal of Operations Research, Volume 8(2), pp. 15-26

Deepradit, S., Pisuchpen, R., Ongkunaruk, P., 2017. The Harvest Planning of Aromatic Coconut by using Monte Carlo Simulation. In: The $20174^{\text {th }}$ International Conference on Industrial Engineering and Applications (ICIEA), Nagoya, Japan, pp. 116-120

Deepradit, S., Pisuchpen, R., Ongkunaruk, P., 2018. The Harvesting Planning of Aromatic Coconut Manufacturing by Considering Uncertainty Harvest Age. In: The 2018 AS Conference, Bangkok, Thailand, pp. 193-202

Dems, A., Rousseau, L., Frayret, J., 2016. A Hybrid Constraint Programming Approach to a Wood Procurement Problem with Bucking Decisions. Constraints, Volume 21, pp. 303317

Dillon, M., Oliveira, F., Abbasi, B., 2017. A Two-stage Stochastic Programming Model for Inventory Management in the Blood Supply Chain. International Journal of Production Economics, Volume 187, pp. 27-41

Doungpattra, N., Jarupan, L., Ongkunaruk, P., 2012. Simulation for Transport Pallet Cost Reduction in Pet Food Manufacturing: An Empirical Case Study. Packaging Technology and Science, Volume 25(6), pp. 311-319

Gajasuta, P., Aungsuratana, A., Saridnirun, P., 2017. Production Capability Enhancemence on Young Coconut Supply Chain for Exportation in Ratchaburi Provincial Areas. Veridian E-Journal, Volume 10(2), pp. 531-545

Govindan, K., Cheng, T.C.E., 2018. Advances in Stochastic Programming and Robust Optimization for Supply Chain Planning. Computers \& Operations Research, Volume 100, pp. 262-269

Ioannou, A., Fuzuli, G., Brennan, F., Yudha, S.W., Angus, A., 2019. Multi-stage Stochastic Optimization Framework for Power Generation System Planning Integrating Hybrid Uncertainty Modelling. Energy Economics, Volume 80, pp. 760-776

Jareonkitpoolpol, A., Ongkunaruk, P., Janssens, G.K., 2018. Determination of the Optimal Blending Problem of Organic-Chemical Fertilizer under Uncertainty. Soil Use and Management, Volume 34(4), pp. 449-460 
Jonkman, J., Barbosa-Póvoa, A.P., Bloemhof, J.M., 2019. Integrating Harvesting Decisions in the Design of Agro-food Supply Chains. European Journal of Operational Research, Volume 276(1), pp. 247-258

Kanjanarat, C., Ongkunaruk, P., 2014. Using Integer Programming Optimization for Aromatic Coconut Supply Planning: A Case Study of a Thai Manufacturer. In: 2014 International Conference on Economics and Management (ICEM2014), pp. 560-564

Kostin, A., Macowski, D.H., Pietrobelli, J.M.T.A., Guillén-Gosálbez, G., Jiménez, L., Ravagnani, M.A.S.S., 2018. Optimization-based Approach for Maximizing Profitability of Bioethanol Supply Chain in Brazil. Computers and Chemical Engineering, Volume 115, pp. 121-132

Limpianchob, C., 2017. Integrated of Harvesting and Production Planning in Aromatic Coconut Supply Chain using Mixed-integer Linear Programming. International Journal of Operational Research, Volume 30(3), pp. 360-374

Miriti, L.K., 2018. Effect of Procurement Planning on Supply Chain Performance of Kenya Medical Supplies Authority. Journal of International Business, Innovation and Strategic Management, Volume 1(4), pp. 1-19

Ogwang, A.O., Waweru, L., 2017. Influence of Procurement Planning on Performance of Kisumu Water and Sewerage Company Limited, Kenya. International Journal of Economics, Commerce and Management, Volume 5(5), pp. 767-789

Ongkunaruk, P., Ongcunaruk, W., 2015. Coconut Sap Pickup Problem with Time Windows: A Case Study. International Food Research Journal, Volume 22(5), pp. 2088-2092

Onyango, C.J., 2012. Effects of Procurement Planning on Institutional Performance: A Case Study of Mombasa Law Court. International Journal of Science and Research (IJSR), Volume 3(358), pp. 2319-7064

Pipatkanaporn, K., 2016. An Overview of Thai Aromatic Coconut Exporting Industry. Master's Thesis, Graduate Program, Thammasart University, Thailand

Pisuchpen, R., Ongkunaruk, P., 2016. Simulation for Production Line Balancing of a Largesized Frozen Chicken Manufacturer. Actual Problems of Economics, Volume 177(3), pp. 397-406

Pradita, S.P., Ongkunaruk, P., Leingpibul, T.D., 2020. Utilizing an Intervention Forecasting Approach to Improve Reefer Container Demand Forecasting Accuracy: A Case Study in Indonesia. International Journal of Technology, Volume 11(1), pp. 144-154

Ratchaburi Provincial Agricultural Extension Office. Available Online at http://www.ratchaburi.doae.go.th, Accessed on June 17, 2020

Richard, O., Koehler, A., 2005. Forecasting, Time Series, and Regression by Bruce Bowerman. $4^{\text {th }}$ Edition. USA: Thomson Brooks Cole

Sawik, T., 2017. Stochastic versus Deterministic Approach to Coordinated Supply Chain Scheduling. Mathematical Problems in Engineering, Volume 2017, pp. 1-15

Make Versus Buy a Decision Framework. Available Online at https://www.academia.edu/28619022/Make_Versus_Buy_A_Decision_Framework, Accessed on December 25, 2019

Vanzetti, N., Broz, D., Montagna, J.M., Corsano, G., 2019. Integrated Approach for the Bucking and Production Planning Problems in Forest Industry. Computers \& Chemical Engineering, Volume 125, pp. 155-163

Wicaksono, F.D., Arshad, Y.B., Sihombing, H., 2019. Monte Carlo Net Present Value for Techno-Economic Analysis of Oil and Gas Production Sharing Contract. International Journal of Technology, Volume 10(4), pp. 829-840 
Willy, K., Njeru, A., 2014. Effects of Procurement Planning on Procurement Performance: A Case Study of Agricultural Development Corporation, Nairobi. International Journal of Business and Commerce, Volume 3(12), pp. 58-68

Yatmo, Y.A., Putra, N., Harahap, M.M.Y., Saginatari, D.P., 2018. Evaluation of Spatial Layout in Health Care Waiting Areas based on Simulation of Droplet Movement Trace. International Journal of Technology, Volume 9(5), pp. 888-897 